\title{
OPTIMIZATION OPERATIONAL PROPOSAL ORGANIZED PUBLIC PORT OF MANAUS (OPPM): A CASE STUDY
}

\author{
Raphael dos Santos Marinhoํㅡㄹ Eduardo de Magalhães Braga ${ }^{2}$
}

\begin{abstract}
${ }^{1,2}$ Programa de Pós-Graduação em Engenharia de Processos do Instituto de Tecnologia da Universidade Federal do Pará (PPGEP/ITECUFPA). Bairro Guamá. CEP: 66075-110. Caixa Postal 479. PABX +55 913201 7000. Belém - Pará - Brasil.
\end{abstract}

Email: rap10marinho2011@hotmail.com

Received: July $23^{\text {th }}, 2019$

Accepted: August $01^{\text {th }}, 2019$

Published: September $30^{\text {th }}$, 2019

Copyright $(\mathrm{C} 2016$ by authors and Institute of Technology Galileo of Amazon (ITEGAM). This work is licensed under the Creative Commons Attribution International License (CC BY 4.0). https://creativecommons.org/lice nses/by/4.0/

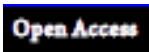

\begin{abstract}
The Manaus Organized Public Port despite its strategic location, daily on its floating docks there is a great number of vessels anchored, an intense flow of people and vehicles of large and small traffic, evidenced the inefficiency of the operational logistics; a wear and tear for PPOM workers and their users who face daily long hours waiting to perform their services of loading and unloading of goods and passengers. The objective of this study was to propose the operational optimization of the Organized Public Port of Manaus (OPPM) in relation to the flow of cargo sent or coming from the interior of the state of Amazonas. Extensive observation of the entire port structure was carried out, as well as an exhaustive review of the literature on the subject. For that, a descriptive research was carried out "in situ" (Organized Public Port of Manaus - OPPM), where an in - depth description of the reality of the current situation was carried out, through photographic reports and records of the problem investigated. After observations was applied action and diagnostic plan tools such as Ishikawa diagram, action plan 5W2H and PDCA cycle. Therefore, with the computerization of data regarding vessels, adoption of fingers at the Torres and Roadway piers and flexibility of opening hours, there is possibility of optimization in the logistic process in PPOM.
\end{abstract}

Keywords: port organization, port of Manaus, port.

\section{PROPOSTA DE OTIMIZAÇÃO OPERACIONAL DO PORTO PÚBLICO ORGANIZADO DE MANAUS (PPOM): UM ESTUDO DE CASO}

\section{RESUMO}

O Porto Público Organizado de Manaus apesar de sua localização estratégica, diariamente em seus cais flutuante há uma grande quantidade de embarcações ancoradas, um fluxo intenso de pessoas e veículos de grande e pequeno porte trafegando, evidenciado a ineficiência da logística operacional; um desgaste para os trabalhadores do PPOM e para seus usuários que enfrentam diariamente longas horas de espera para realizar seus serviços de embarque e desembarque de mercadorias e passageiros. O objetivo deste estudo foi propor a otimização operacional do Porto Público Organizado de Manaus (PPOM) em relação ao fluxo de cargas enviadas ou advindas do interior do estado do Amazonas. Foi realizada extensa observação de toda a estrutura do porto, assim como uma exaustiva revisão de literatura sobre o tema. Para tal foi realizada uma pesquisa descritiva "in situ” (Porto Público Organizado de Manaus - PPOM), onde foi realizada uma descrição aprofundada da realidade da situação atual, através de relatos e registros fotográficos da problemática averiguada. Após observações, foi aplicado ferramentas de plano de ação e de diagnóstico, como diagrama de Ishikawa, plano de ação 5w2h e ciclo PDCA. Portanto, com a informatização de dados referentes às embarcações e flexibilização do horário de funcionamento, há possibilidade de otimização no processo logístico no PPOM

Palavras - chaves: Organização potuária, Porto de Manaus, Porto. 


\section{INTRODUÇÃO}

A região Amazônia representa uma grande extensão territorial do Estado brasileiro, é rica em recursos naturais, entretanto, possui um histórico de ocupação desorganizada; possui um setor de transporte alicerçado na modalidade hidroviária, assumindo um papel relevante no que concerne a busca do entendimento dos fluxos de cargas pessoas oriundas dessa ocupação [1].

A Amazônia é um labirinto de rios, paranás, lagos, igarapés e furos, portanto, entender a sua dinâmica de mobilidade é essencial, visto que, é o rio que comanda a vida não só do ribeirinho, mas também que dá vida a via transporte de cargas e passageiros que atravessam a imensidão dos rios de uma comunidade ou de uma cidade a outra [2]. Por conseguinte, o transporte fluvial na Amazônia devido as características hidrográficas únicas, é a vida social e economia [3].

O PPOM apesar de sua localização estratégica, diariamente em seus cais flutuante há uma grande quantidade de embarcações ancoradas, um fluxo intenso de pessoas e veículos de grande e pequeno porte trafegando, evidenciado a ineficiência da logística operacional; um desgaste para os trabalhadores do PPOM e para seus usuários que enfrentam diariamente longas horas de espera para realizar seus serviços de embarque e desembarque de mercadorias e passageiros.

Segundo a pesquisa do Sindicato das Empresas de Navegação Fluvial no Estado do Amazonas [4], em parceria com Instituto de Pesquisa em Transportes (Intra), há uma desorganização no transporte fluvial misto (cargas e passageiros), nos rios que cercam o estado Amazonas. Embora as infraestruturas de transportes novas (portos) e do crescimento da oferta de embarcações, há inúmeras cidades e rotas que estão mal organizadas e não possuem de mecanismos de coordenação apropriados para fazer uso eficiente de tais recursos disponíveis.

No primeiro semestre de 2018, a região amazônica realizou a movimentação de 6,1 milhões de toneladas, com participação de mercado de $48,5 \%$ e crescimento de $16,8 \%$. Evidenciando a região amazônica como um dos principais rios de transporte de carga no Brasil. Neste cenário, destaca-se a soja com $24,6 \%$ de crescimento, sendo responsável pelo transporte de 4,3 milhões de toneladas no período supracitado, contribuindo desta forma com 70,8\% de participação no transporte total na região no que se refere a navegação interior, seguido de petróleo e seus derivados com 573 milhões de toneladas com contribuição de 9,3\% para o abastecimento eficaz de toda a região amazônica [5].

O objetivo deste estudo é relatar a proposta de otimização operacional do Porto Público Organizado de Manaus (PPOM) em relação ao fluxo de cargas enviadas ou recebidas do interior do estado do Amazonas.

\section{DESENVOLVIMENTO}

\section{II.1 NAVEGAÇÃO NA AMAZÔNIA: VIDA SOCIAL E ECONÔMICA}

O Brasil possui uma extensa malha hidroviária com 63 mil km de rios e lagoas/lagos, desta totalidade, mais de 40 mil km encontram-se na Amazônia, dentre as principais bacias hidrográficas brasileiras, a bacia Amazônica apresenta uma extensa malha hidroviária navegável $(18.300 \mathrm{~km})$ [6,7].

A Região Hidrográfica Amazônica (Figura 1) representa aproximadamente $40 \%$ do Estado brasileiro e detém um pouco mais de $60 \%$ de toda a disponibilidade hídrica do País. Os recursos hídricos desta região, são fartos e até hoje pouco explorados. A
Região Hidrográfica Amazônica, possui uma região de grandes contrastes humanos e naturais [6].

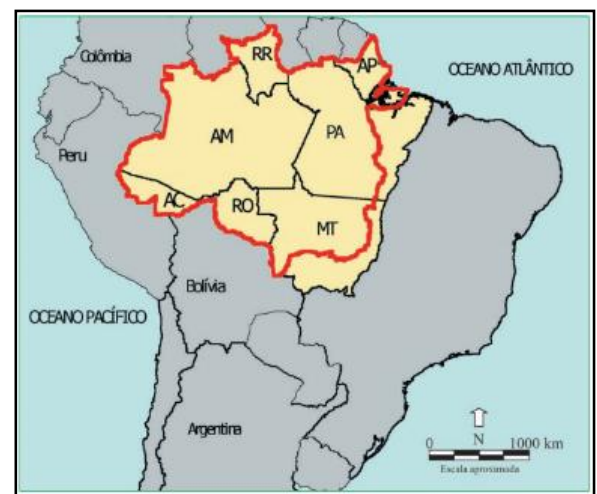

Figura 1: A região hidrográfica amazônica (linha vermelha) no quadro da América do Sul.

Fonte: Brasil, (2006).

A Região hidrográfica amazônica é constituída pela bacia hidrográfica do Rio Amazonas, dos rios da ilha Marajó e pelas bacias localizadas no Estado do Amapá que desembocam no oceano atlântico. No tocante a recursos hídricos, a contribuição média em território brasileiro é de $133.000 \mathrm{~m}^{3} / \mathrm{s}$ (73\% do total do País). Já a contribuição adicional de territórios alóctones para as vazões da região hidrográfica é de $76.000 \mathrm{~m}^{3} / \mathrm{s}$. As maiores demandas por uso da água na região ocorrem nas sub-bacias dos rios Negro, Madeira e Tapajós, e se referem a atualização para irrigação (39\% da demanda total). Ainda dentro deste cenário, a demanda urbana representa cerda $17 \%$ da demanda da região (11 $\left.\mathrm{m}^{3} / \mathrm{s}\right)[8]$

A Hidrovia do Amazonas é a principal rota de defluência de cargas, sendo responsável por aproximadamente de $65 \%$ do total de cargas transportadas na região. Anualmente a média de movimentação de cargas tem sido da ordem de 50 milhões de toneladas desde o início da década. Na Amazônia o transporte fluvial é diversificado e atente a uma abrangente região florestal fechada e cheia de rios. A hidrovia é essencial para o comércio externo e interno, visto que, garante a oferta de produtos com preços mais competitivos. Sendo importante relatar que atualmente a infraestrutura hidroviária da região é composta por decursos de rios canalizados e por vias de navegação em fluxo livre [9].

O sistema de transporte fluvial estadual proporciona ligações entre vários municípios de um mesmo Estado, ou seja, os trechos estaduais ou intermunicipais, representam cerca de $72 \%$ do total do conjunto de rotas para passageiros e $77,77 \%$ do total de trechos de caminhos de cargas no estado do Amazonas [4]

O transporte de produtos e pessoas na Amazônia é realizado em seu maior percentual é via fluvial, diferente dos outros estados, que tem como o seu principal transporte o rodoviário. Isto é comprovado pela grande quantidade de pessoas, produtos agrícolas e peixes que chegam todos os dias a Manaus, vindo de diversos municípios [3]

O transporte aquaviário na Amazônia tem uma característica bastante peculiar, ou seja, grande parte das embarcações transporta passageiros e cargas ao mesmo tempo, entretanto estas cargas são mais leves do que as transportadas por embarcações que realizam este trabalho exclusivamente de cargas. No entanto, ocupam um espaço bastante vultuosos nos porões dos barcos, e muitas vezes até em locais destinados aos passageiros, tornando, portanto, a viagem perigosa e mais demorada [3]. 


\section{II.2 IMPORTÂNCIA ECONÔMICA DOS PORTOS}

Os portos são áreas que estão conectadas ao mar, oceano ou rio, ligando vias navegáveis e são consideradas como entidades. Eles são equipados com infraestrutura e instalações técnicas de qualquer tipo que lhes permitam gerenciar o tipo de carga para o qual são especializados. Sua função básica é fornecer abrigo em diferentes graus aos navios, permitindo a transferência de mercadorias de um meio de transporte para outro. Eles também funcionam como um nó entre o mar e a terra e são um exemplo claro de intermodalidade $[11,12]$.

Neste ínterim, há ainda efeitos no contexto local no que tange a movimentação portuária que se encontra diretamente relacionada com a oferta de emprego na região. Entretanto, essa oferta de empregos dependente dos setores que o porto atua, ou seja, portos especializados em transporte de contêineres tem duas mais ofertas de emprego do que portos especializados em cargas de granel líquido e sólido. Já no contexto do comercio internacional, o aumento do papel da logística internacional e realocação espacial da produção, aumento dos navios, conteinerização e o papel do transbordo, integração vertical, fusões e aquisições e terceirização da atividade logística $[13,14]$.

Embora existam grandes áreas metropolitanas sem um porto, seu destino é muitas vezes fortemente dependente da qualidade da conexão com os portos. Quanto menor e mais próxima a cidade portuária em relação à metrópole interior, mas ela pode ser considerada como parte dessa metrópole. Poderia então ser considerado satélites dependentes, corredores de curto alcance ou corredores de longo alcance [15].

\section{II.3 LOGÍSTICA E GESTÃO PORTUÁRIA}

A logística é considerada como uma das áreas mais importantes da gestão empresarial e abrange elementos relevantes da administração empresarial, como: processamentos de pedidos, estoques, transporte, armazenamento, manuseio de insumos e embalagem, que se encontram integrados a uma rede de instalações. A logística trata sobre a responsabilidade de administração e delineação de sistemas com objetivo de controlar estoque, transporte e a localização geográfica pelo menor custo total [16].

A logística é um processo que abrange ações importantes para a disponibilização de serviços e bens aos clientes quando e onde esses clientes quiserem adquiri-los. Entretanto, tal conceito deixa claro que a logística é parte da Cadeia de Suprimentos não um processo particular e inteiro, neste contexto é que o gerenciamento da cadeia de suprimentos (GCS) ou Suply Chain Management (SCM) [17].

As cadeias de gerenciamento são uma das melhores formas de promover a competitividade no mercado. Alcançar uma cadeia suprimentos dominante demanda esforços e parcerias especificas e infraestrutura correta para fazê-la acontecer. Portanto, a GCS encontra-se baseada em mudanças de infraestrutura entre companhias e não pode jamais ser um conceito vago [18].

O crescimento econômico dos países tem como uma de suas conjecturas a expansão e o desenvolvimento do comércio externo. As políticas dirigidas ao setor portuário desempenham, neste tocante, um papel estratégico no pressuposto econômico brasileiro. É sabido que o setor portuário é atualmente como um dos principais obstáculos do comércio internacional no Brasil, especialmente em razão da pouca eficiência e dos altos custos nas atividades portuárias [19].
Trazendo para o contexto portuário, com a Lei $\mathrm{n}^{\circ}$ 8.630/1993 (Lei dos Portos) e o Decreto n. 6.620/2008, o setor portuário brasileiro tinha o objetivo o aumentar a competitividade através das reduções de custos. Antes da promulgação da lei e decreto citados, as operações portuárias brasileiras eram geridas pelas Companhia das Docas, sindicatos dos trabalhadores portuários e empresas de economia mista. Tal sistema resultou em portos poucos eficientes, mal administrados e de custos elevadíssimos, além da defasagem tecnológica e escassez de recursos estatais.

\section{METODOLOGIA}

Este trabalho adotou a metodologia de estudo de caso. Portanto, a pesquisa foi de campo, observacional, explicativa, descritiva de abordagem quali-quantitativa, ou seja, uma pesquisa que não almejou realizar intervenções diretas e imediatas no local alvo deste estudo, e sim angariar dados e com isso realizar analises críticas e com isso elaborar uma proposta de melhoria dos pontos críticos encontrados.

A coleta de dados foi realizada durante a pesquisa de campo, observacional e descritiva realizada in loco, ou seja, em dias comerciais (segunda a sexta) durante o processo que carregamento/descarregamento de mercadorias vinda ou advindas do interior do Estado do Amazonas. Os dados foram armazenados em planilhas, atas e relatórios diários de observação, sendo relevante relatar que os dados foram tratados de maneira qualiquantitativa a fim de proporcionar subsídios para a elaboração da proposta de otimização da logística operacional do PPOM.

As observações e análises dos processos de transporte, manipulação e armazenamento foram realizadas após a aplicação do questionário. Foram utilizados como instrumentos de coleta de dados para esta pesquisa:

\section{III.1 PORTO PÚBLICO ORGANIZADO DE MANAUS}

O Porto Público Organizado de Manaus (PPOM) encontra-se situado à margem esquerda do Rio Negro, no centro da cidade de Manaus no estado do Amazonas, distando $13 \mathrm{~km}$ da confluência com o Rio Solimões. A sua administração é realizada pela Sociedade de Navegação, Portos e Hidrovias do Estado do Amazonas (SNPH), por representação ao Estado do Amazonas(Figura 2). Em relação a posição geográfica, o PPOM situa-se nas seguintes coordenadas: Latitude Sul $03^{\circ} 08^{\prime} 03^{\prime}$; Longitude Oeste $60^{\circ} 01^{\prime} 46^{\prime}$ '. Sendo que a área de expansão é determinada pelas coordenadas: Latitude Sul 308'04"; Longitude Oeste 5956'40" (SNPH, 2012).

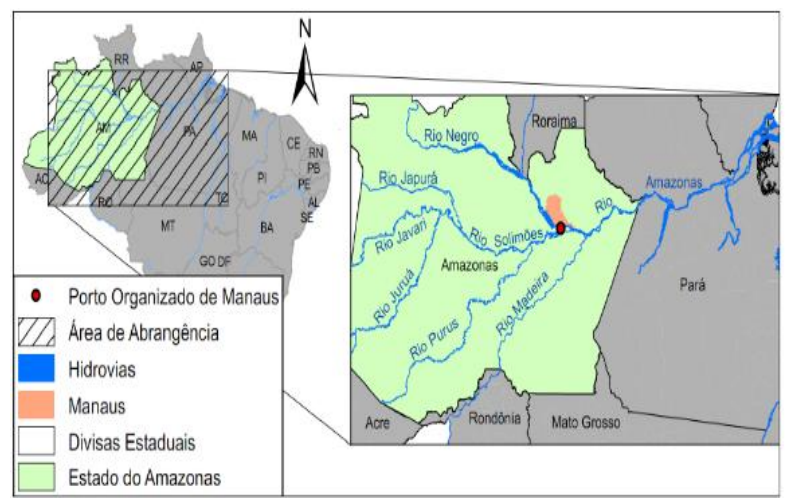

Figura 2: Localização do Porto Público Organizado de Manaus. Fonte: Porto Público Organizado de Manaus, (2018). 
Em média, entre 2014 a 2018, houve a atracação de 4.704 embarcações, com saldo de aproximadamente 112 diferentes embarcações mensalmente, com capacidade de amarração de 24 barcos no total e cerca de 16 amarrações ao dia. Em média o tempo de permanência de embarcações no cais é 3 dias. A área de influência do PPOM compreende os estados do Amazonas, Pará e Rondônia.

Diariamente para adentrar no PPOM, os motoristas dos veículos precisam se dirigir ao Posto 2 para realizar a compra do bilhete para ter o acesso aos cais (Figura 3). Os veículos são organizados em duas filas: uma fila para veículos de pequeno porte e a segunda para veículos de grande porte.

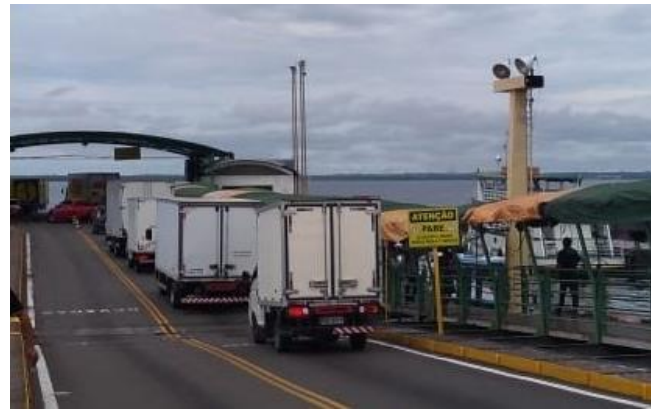

Figura 3: Usuários em espera no Posto 2. Fonte: Marinho, (2019).

Na figura 4, é possível verificar problemas em relação a vaga de estacionamentos disponível para carga/descarga de veículos que chegam, pois nem sempre as empresas conseguem (de todos os tipos e portes) realizar suas atividades de forma rápida e devido a isso passam mais tempo estacionados, afetando diretamente ao fluxo de veículos e pessoas dentro dos cais, causando o deslocamento maior de cargas, ou seja, o que poderia levar apenas alguns minutos, leva em média duas horas ou mais, dependendo do volume das cargas e rapidez dos carregadores.

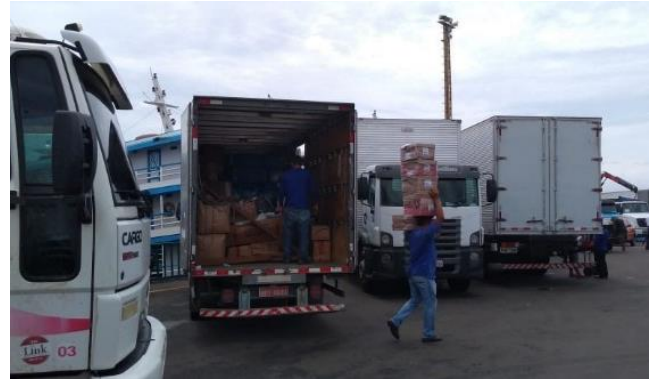

Figura 4: Caminhão esperando para ser descarregado. Fonte: Marinho, (2019).

\section{ANÁLISE DE DADOS}

Em um primeiro momento para detecção dos problemas da empresa, foi realizada relatório sobre observação in loco, registros fotográficos e dados coletados na entrevista com os armadores. Após observações, foi aplicado ferramentas de plano de ação e de diagnóstico, como diagrama de Ishikawa, plano de ação 5w2h e ciclo PDCA.

Após a realização do Diagrama de Ishikawa, foi possível identificar que o PPOM apresenta uma logística ineficiente para a entrada de veículos, mesmo sem uso da balança, falta de controle quanto a quantidade de veículos estacionados dentro do cais por horas, não apresenta informações sobre as embarcações (se são mistas ou apenas para transporte de passageiros), o que ocasiona o deslocamento de mais pessoas e veículos dentro dos cais. $\mathrm{O}$ número total de atracamento ainda é limitado devido à falta de fingers, em relação aos horários, ainda que funcionem em horários comercial (07:00 as 17:00 hs) ainda há todos os dias empresas que demoram horas para realizar suas atividades e por vezes precisam voltar duas três vezes por dia para tal.

Um passo seguinte no diagnóstico das falhas do processo produtivo foi determinar todos os responsáveis neste processo, suas responsabilidades e setores. Desta forma foi elaborado o plano de ação 5W2H objetivando visualizar estes aspectos. Onde foi estipulado as atividades a serem efetuadas com a maior clareza possível, e serão determinados prazos, responsáveis, local, data, o porquê da realização desta ação e os custos. Neste caso, será realizado três planos de ação baseados no $5 \mathrm{~W} 2 \mathrm{H}$.

Após a criação do diagrama de Ishikawa e da ferramenta 5W2H, se construiu o Ciclo PDCA, com intuito de padronizar informações, diminuir as chances de erros, e, de modo consequente, evitando desperdícios de insumos, recursos financeiros e humanos. Fazendo com que as informações sejam mais claras e compreensíveis para todos os setores envolvidos.

O primeiro ponto a ser proposto é a melhoria quanto ao sistema informatizado das embarcações mistas que atracam diariamente nos cais do PPOM, visto que, os vendedores de passagens dessas embarcações se situam próximo ao PPOM na rua 15 de novembro e avenida Lourenço da Silva Braga, no total são 11 agências que vendem passagens para múltiplas embarcações, entretanto, muitas das embarcações já possuem um guichê dentro do PPOM, mas as informações referentes as embarcações, horário de saídas, tempo de viagem, preços, dados técnicos como capacidade média de passageiros, escalas e se levam carga, só pode ser conhecidas indo até os guichês do PPOM ou com algum vendedor próximo ao porto ou próximo a feira da Manaus Moderna.

A proposta supracitada visa, sobretudo, a disponibilização de informações para ajudar quanto maior controle do conhecimento das embarcações que se encontram com as normas estipuladas pela Capitania Fluvial da Amazônia Ocidental (CFAOC), Agência Nacional de Transportes Aquaviários (Antaq) e Instituto de Pesos e Medidas do Amazonas (IPEM)

Proporcionando maior agilidade para o cliente que tem interesse de utilizar os serviços do PPOM, em especial, pequenos empresários, produtores e até mesmo pessoas que precisam enviar ou receber uma mercadoria advinda ou enviada do interior do Amazonas ou de outro estado, sem, contudo, precisar se deslocar até o PPOM, porque também seria disponibilizado os números de contato (Figura 5).

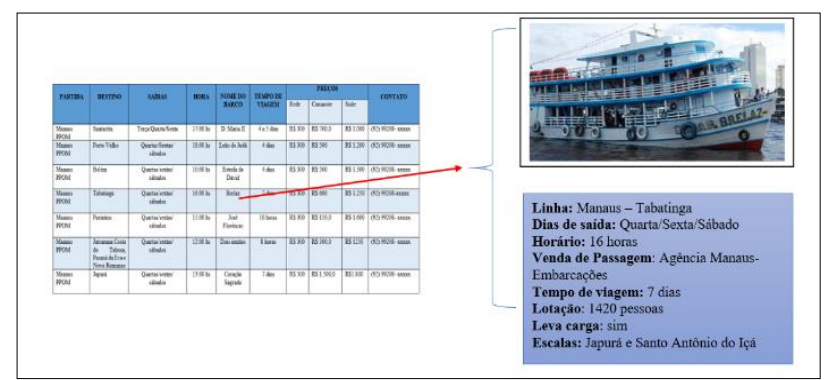

Figura 5: Exemplo de dados específicos sobre uma embarcação. Fonte: Marinho, (2019).

Em relação a possibilidade da otimização do tempo através de flexibilização do horário de movimentação, como o Porto funciona $7 \times 24,7$ dias por semana e 24 horas. Diante do exposto, a proposta sugerida é o agendamento de horário das empresas que mais utilizam o PPOM mediante aceitação dos 
armadores das embarcações. Esta modificação atenuaria o grande fluxo de veículos entre às 07:00 da manhã e 17:00 horas.

Tal mudança seria benéfica para os armadores que poderiam demorar menos tempo atracados, visto que, as três empresas mais citadas realizam o fornecimento de mercadorias em média 2 a 3 vezes por semana em horários distintos. Portanto, para tal prática ser mais viável para o empresário que teria que deslocar seus funcionários em horários diferentes, seria sugerido descontos de $20 \%$ em cima dos valores tabelados.

\section{CONCLUSÃO}

Foi possível observar que o PPOM é um porto de grande importância econômica para todo o Estado, é um porto competitivo, entretanto, há gargalos que precisam ser resolvidos para que seja um porto ainda mais competitivo e consequentemente possa oferecer serviços de qualidade para todos os clientes que se utilizam dele.

Através das observações foi possível propor sugestões de melhoria na estrutura física, no processo de informatização de dados referentes às embarcações assim como a sugestão de melhorias quanto a dinamização do tempo de escoamento de mercadorias para o interior do Estado. A disponibilização de dados no site do PPOM traria mais segurança e comodidade aos clientes, pois reuniria em um só lugar todas informações necessárias para usufruir de um bom atendimento. Em relação a otimização de tempo, esta sugestão facilitaria tanto para os armadores quanto para os empresários, visto que, pouparia tempo de espera e ainda geraria economia de até $20 \%$ nos serviços do PPOM.

Sendo importante relatar que o uso das ferramentas (Diagrama de Ishikawa, 5W2H e Ciclo PDCA) foram essenciais para traçar os principais problemas no dia a dia do PPOM, e com isso foi possível propor com mais segurança as sugestões de melhoria do processo operacional do Porto Público Organizado de Manaus.

Entretanto, é sabido que a adoção das sugestões deste estudo no processo operacional do PPOM é de responsabilidade das empresas arrendatárias, visto que, para a incorporação destas ideias é necessário que estejam em conformidade com os seus objetivos empresariais. Considerados tais aspectos, deve-se frisar que este estudo serviu para demonstrar perspectivas de melhoras no processo de trabalho do PPOM e com isso a possibilidade de aumento de competitividade e consequentemente lucratividade da empresa arrendatária e melhor qualidade de serviços oferecidos para sociedade amazonense.

\section{REFERÊNCIAS}

[1] A.V. Morgado. L. S. Portugal, A.J.R. Mello. Acessibilidade na Região Amazônica através do transporte hidroviário. Journal of Transport Literature, 7(2), p.p. 97-123.

[2] M.I. Araújo, S.G.A. Sousa, M.A.G Amaral, Dias R.S. Navegando de acordo com a "lei do rio". Anais do V Congresso Internacional de Geografia da Saúde. Manaus: CIGEO, 2014, p.p. $1-14$.

[3] R.C.A. David. A dinâmica do transporte fluvial de passageiros no estado do amazonas. 122 f, 2010. Dissertação (Mestrado em Geografia) - Universidade Federal do Amazonas. Manaus, 2010.

[4] Sindicato das empresas de navegação fluvial no estado do amazonas. Pesquisa SINDARMA: Transporte Hidroviário Interior de Passageiros e Disponível em
http://www.sindarma.org.br/Pesquisa_Sindarma.pdf> Acesso em: 07 de outubro de 2018, 22h34min.

[5] Brasil. Boletim Aquaviário do $2^{\circ}$ trimestre de 2018. Agência Nacional de Transportes Aquaviários - ANTAQ. Disponível em <http://portal.antaq.gov.br/wpcontent/uploads/2017/03/Boletim-Informativo-

2\%C2\%BAT2018-vfinal.pdf> Acesso em: 28 set. 2018, $13 \mathrm{~h} 33 \mathrm{~min}$.

[6] Brasil. Caderno da região hidrográfica amazônica. Ministério do Meio Ambiente, Secretaria de Recursos Hídricos. Brasília: MMA, 2006.

[7] M. J. C. Bueno, G. G. R. Silva, C. F. Stettiner, L. N. Marcellos, F. G. Sardeiro. Modal fluvial na Amazônia: desafios e oportunidades. Revista Eletrônica da Faculdade de Ciências Exatas e da Terra Produção/construção e tecnologia, 3(5), p.p. 1-10, 2014.

[8] Agência Nacional de Transportes Aquaviários. Presidência da República. Secretaria de Portos. Agência Nacional de Transportes Aquaviários Caracterização da oferta e da demanda do transporte fluvial de passageiros da região amazônica. Brasília: ANTAQ, 2013.

[9]Agência Nacional de Águas. Região hidrográfica amazônica. Disponível em: <http://www2.ana.gov.br/Paginas/portais/bacias/amazonica.aspx \#> Acesso em: 28 set. $2018,13 \mathrm{~h} 33 \mathrm{~min}$.

[10] Agência Nacional de Águas. Hidrovia SolimõesAmazonas. 2016.2 Disponível em <http://www.dnit.gov.br/hidrovias/hidrovias-interiores/hidroviado-solimoes-amazonas > Acesso em: 26 set. 2018, 10h43min.

[11] S. Tarantola. Puertos como nodos integrados a la cadena logística. Informe especial: Intermodalismo y Logística Internacional, 6(5), p.p. 1-5, 2005.

[12] I. Roa, Peña Y, B. Amante, M. Goretti. Ports: definition and study of types, sizes, and business models. Journal of Industrial Engineering and Management, 6(4), p.p. 1055-1064, 2013.

[13] O. Merk. The competitiveness of global port-cities: synthesis report. Netherlands: OECD, 2014.

[14] P. W. De Langen, E. Haezendonck. Ports as clusters of economic activity. The Blackwell companion to maritime economics. 1. ed. Nova Jersey: Wiley-Blackwell, 2012.

[15] O. Merk., C. Ducruet C., P. Dubarle, E. Haezendonck, M. Dooms. Competitiveness of port-cities: the case of the seine axis (Le Havre, Rouen, Paris, Caen) - France. Netherlands: OECD, 2011.

[16] D. J. Bowersox, D.J. Closs, B. Cooper, J. C. Bowersox. Gestão logística da cadeia de suprimentos. 4. ed. Porto Alegre: AMGH, 2013.

[17] R. Ballou. Gerenciamento da cadeia de suprimentos. $5^{\mathrm{a}}$ ed. Porto Alegre: Bookman Companhia, 2006.

[18] A.C. Farranha, C.S. Frezza, F. O. Barbosa. Nova lei dos portos: desafios jurídicos e perspectivas de investimentos. Revista Direito GV, 11 (1), p.p. 089-116, 2015.

[19] G. Macohin, G. Compras, contratações e terceirizações. 1ed. Curitiba, PR: IESDE Brasil, 2012. 